\title{
Women Participation in Urban Agriculture and its Influence on Family Economy - Sri Lankan Experience
}

\author{
M. I. Gamhewage ${ }^{1}$, P. Sivashankar ${ }^{1}$, R. P. Mahaliyanaarachchi ${ }^{1}$, \\ A. W. Wijeratne ${ }^{1}$ and I. C. Hettiarachchi ${ }^{1}$ \\ Received : 05 $5^{\text {th }}$ May 2015 / Accepted : $24^{\text {th }}$ August 2015
}

\begin{abstract}
Urban Agriculture has an incredible ability to address various burning issues in the urban community such as poverty, malnutrition, unhygienic food stuff and food insecurity which have arisen due to the continuous increase in global urban population. Women can play a key role in urban agriculture due to their role in food management at household level. Nevertheless, at present women participation in urban agriculture is significantly unsatisfactory. In this research, primary data were collected from a sample of 82 respondents in the capital of Sri Lanka, Sri Jayawardanepura Kotte. The results of the study confirm a significant difference in the perceptions on urban agriculture among urban women farmers and urban women non-farmers. The most influential socio-economic factors affecting the women participation in urban agriculture are; age, education level, number of members in the family and total cultivable area. The time constraints for farming, poor quality of planting inputs and lack of knowledge are the mainly identified constraints that hinder women's contribution in urban agriculture. The results of the study further reveal that the best strategy practiced by the urban women farmers to uplifting the family economy is re-investing the income or savings of household expenditure due to urban agriculture activities on same agricultural activities. Further, the fitted model on can be used to determine the level of women participation in urban agriculture.
\end{abstract}

Keywords: urban Agriculture, family economy, socio-economic factors, urban women farmers, factor analysis

\section{INTRODUCTION}

The concept of urban agriculture (UA) has been defined in many ways. "Urban agriculture is an industry located within (intra-urban) or on the fringe (peri-urban) of a town, a city or a metropolis, which grows or raises, processes and distributes a diversity of food and nonfood products, (re)using human and material resources, products and services found in and around that urban area, and in turn supplying human and material resources, products and services largely to that urban area" (Mougeot, 2000). Urban agriculture has become one of the fastest emerging trends, especially in the developing world where urban agriculture grows at 3.5 percent annually. This is due to the continuous growth of urban population (Eawag, 2007).

The urbanization process has gradually increased the urban poverty. Increasing urban poverty simultaneously has increased the malnutrition and food insecurity in the urban areas (Baker, 2012; Zezza and Tasciotti, 2010; Mougeot, 2000). One of the best strategies to eradicate urban poverty via uplifting the family economy while ensuring food security and enhancing nutrition level of the family is Urban Agriculture (Baker, 2012; Doss et al., 2010; Zezza and Tasciotti, 2010). The development of low or no space within the family business 
garden concept is identified as one of the best innovations available in the urban agriculture development arena (Ranasinghe, 2009).

Over the last two decades, evidence has been scattered regarding the importance of women participation in urban agriculture. Some studies document that women's predominance of urban agriculture in Zimbabwe (Chaipa and King, 1997) and particularly in the African context (Cockram and Feldman, 1996). Kutiwa et al. (2010) and Mougeot (2000), have pointed out that urban agriculture provides women, the opportunity of earning a secondary income, improve nutritional value of the household diets, and participate actively in budgeting and decision making processes. Kutiwa et al.,(2010) has revealed that women participate in urban agriculture, more actively than men due to three main reasons. The primary reason is that urban agricultural activities go hand in hand with daily household activities of women. When the vegetable plots and/or animal units like poultry etc. are situated in their home gardens, they can attend on urban agricultural activities such as providing kitchen wastage as feed to animals or fertilizer, watering and so on easily when they get a break from other household activities (Kutiwa et al., 2010). Bryld (2003) and Kutiwa et al. (2010) have stated that urban men do not consider urban agriculture as a source of income and they merely consider urban agriculture as a marginal activity. This has been considered as the secondary reason for women domination in urban agriculture. According to Kutiwa et al. (2010) and Obuobie (2004), the tertiary reason is that societies expect women to hold the responsibility of providing secured food supply to the family. Hence women participation is crucial in urban agriculture. Urban agriculture is obviously one of the best strategies to overcome the urban poverty and food insecurity. On the other hand, the responsibility in providing food and welfare to the household is on the shoulders of women in most of the societies around the world (Adedayo and Tunde 2013). Moreover, the micro finance generated by urban agriculture can be used to enhance the economical status of the household (Zezza and Tasciotti 2010).
So, the role of women in urban agriculture is undoubtedly decisive in strengthening the household economy while ensuring the food security of the family.

Studies conducted in Ghana (Maxwell et al., 1998) and in United States of America (Anríquez, 2010) have identified the constraints faced by urban women farmers which hamper their participation in urban agriculture activities. Studies regarding the women participation in urban agriculture are lacking in Sri Lanka. Given this context, the aim of this research is to fill this knowledge gap and to contribute to the global knowledge base in urban agriculture.

\section{Research Problem}

Role of women are decisive in urban agriculture, since agricultural activities can often be straightforwardly combined with their role in managing household economy. This provides them a better opportunity for additional income generation by selling the excess production while catering the own household demand for fresh and nutritious food by involving in urban agriculture. At the same time, involving in urban agriculture makes available them with both mental and physical satisfaction. Despite this huge potential participating in urban agriculture by women is marginal.

The main objective of this research is to assess the women participation in urban agriculture and its influence on the family economy. The specific objectives are to (a) assess the perceptions about urban agriculture among urban women farmers and urban women non-farmers, (b) to determine the effect of socio economic factors on the women participation of urban agriculture, (c) to develop a model to determine the level of women participation in urban agriculture, (d) to identify the benefits obtained by urban agriculture and how those benefits are used to increase the family economy and (e) to assess the constraints facing women urban farmers which hinder women participation in urban agricultural activities. 


\section{MATERIAL AND METHODS}

This section outlines the materials and methods applied in the research. The deductive approach was used in this research. Bryman (2012), has implied that deductive approach explains the causal relationship between variables and is appropriate for social science researches. Survey was used as the research strategy. Data were collected by using triangulation method. Kutiwa et al. (2010) and De Cuir-Gunby et al. (2012) have highlighted the importance of using triangulation method in collecting qualitative and quantitative data in order to give a statistical and conceptual significance to the research.

\section{Data collection}

The study was conducted in Sri Jayawardanapura Kotte Municipal Council area which is the administrative capital of Sri Lanka. It is one of the most urbanized areas in Sri Lanka with a population of 107,144 (Department of census and statistics, 2012). There were 26,988 household units in the sample frame and assumed at least one woman is present in each household unit. According to the information obtained from the Name Registry belong to Agriculture Instructor of Sri Jayawardanapura Kotte, there were 384 women who were engaging in urban agriculture under the Urban Agriculture projects of Department of Agriculture, specifically the "DiviNeguma Program". So, the 384 women were taken as the probable elements of urban agriculture women. A total of 82 women were taken as the sample of both urban women farmers and urban women non farmers. Out of 82 , fifty percent of respondents were urban women farmers and the rest were urban women non-farmers. Both quantitative and qualitative data were collected and qualitative data were used as aidinterpretation.

The data on the perception about urban agriculture among urban women farmers and urban women non-farmers were measured by using 5-point likert scale. Hampson et al., (2003) have proved that likert scale is one of the best two approaches to measure the perception. The non- parametric Mann-Whitney test was used to analyze the two samples. The recommended two sample location tests for non-parametric data are, Mann-Whitney test, Wilcoxon test and Tukey's quick test. Kruskal Wallis and median tests are used to analyze more than two samples. According to Hart (2001), Mann-Whitney test is one of the most powerful non parametric tests and can be used as the best alternative to the parametric t-test when the data are not normally distributed (non-parametric).

A significant fraction of urban women are not participated in urban agriculture. The decision for participating in urban agriculture is greatly affected by variety of factors which can be sorted into three categories namely; socio-economic factors, perception on urban agriculture and the constraints which hinder the efforts of women in participating in urban agriculture.

The socio-economic factors greatly influence on the availability of resources such as human resources, time, investments, access to land area (space for urban agriculture) and knowledge practice in urban agriculture. If the socioeconomic factors mentioned in the conceptual framework are in positive conditions, it stimulates the participation of women in urban agriculture; but in contrast, if the factors are negative, it can be acted as barriers for women to engage in urban agriculture. Furthermore, the importance of urban agriculture for a family, especially to uplift the household economy is perceived differently by different urban women. These alterations have significantly affected their decision in participating in urban agriculture. The figure 01 shows the conceptual framework of the research. 


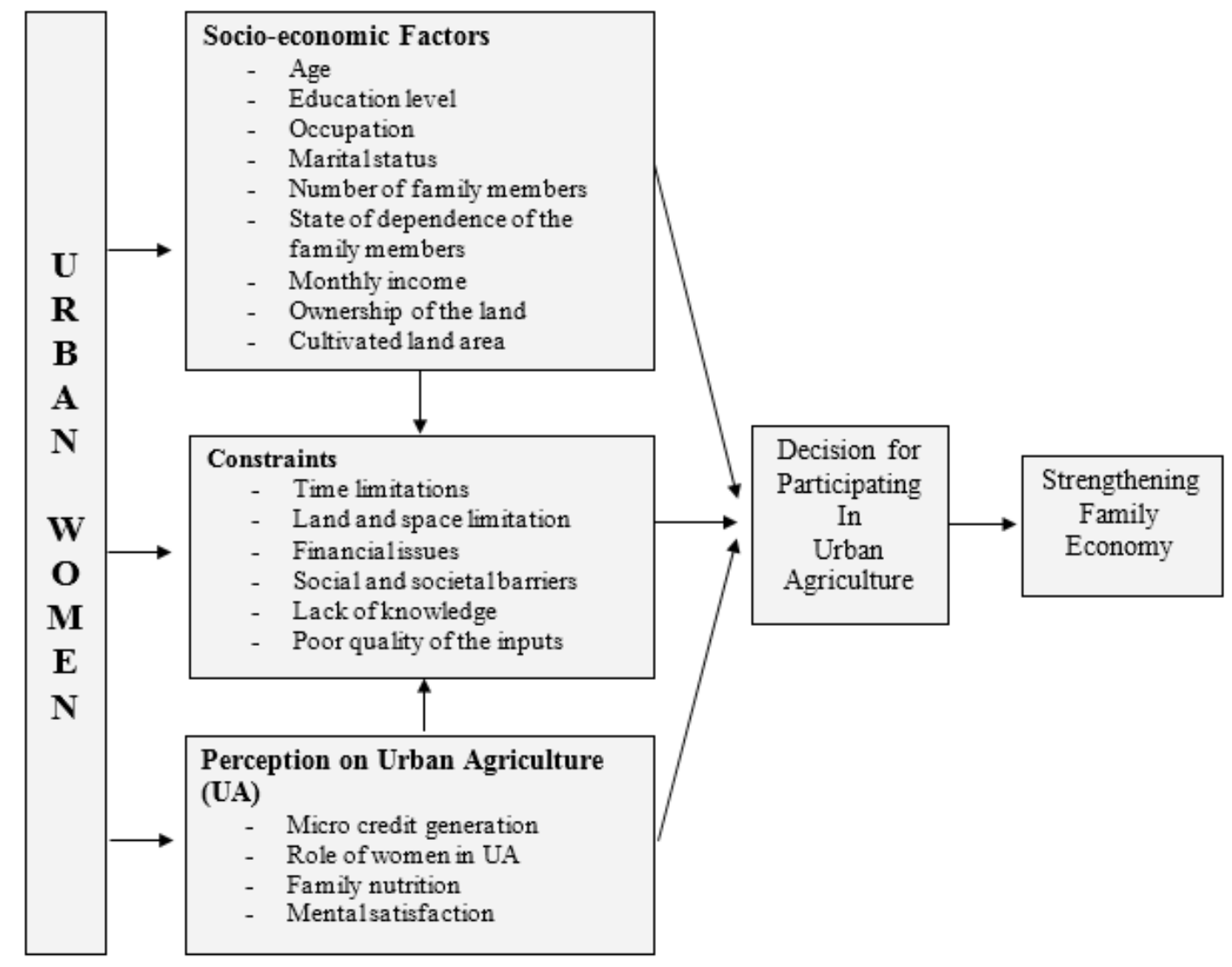

Figure 01: Conceptual Framework

\section{RESULTS AND DISCUSSION}

This section is organized in order to present the findings according to the pre-defined objectives of the research.

\section{Perception on Urban Agriculture among urban women}

Table 01 depicts the results of the MannWhitney test for perception on urban agriculture among urban women. Urban women farmers have recognized urban agriculture as a method of micro credit generation and they were certain that urban agriculture as a good strategy to cope with situations of food crises. The urban women non-farmers showed a negative attitude towards the above mentioned statements.

Moreover, results depict that urban women farmers were aware that urban agriculture can be started and continued at any time of the year and it can be effectively managed with available limited resources. The counterpart representing the urban women non-farmers were not aware about this possibility. Women who were engaged in urban agriculture were certain that urban agriculture as a good strategy to cope with situations of food crises whereas the other party was uncertain about it.

Furthermore, urban women farmers have accepted that urban agriculture is a good method of landscaping and it provides mental satisfaction in order to reduce stress levels of the urban lifestyle. Urban women farmers did not consider engaging in urban agriculture as a disturbance to their domestic activities and duties. Most importantly, they believed that the role of women in urban agriculture is crucial. The urban women non-farmers were not aware about the above mentioned aspects. 
Nevertheless, both parties accepted that urban agriculture is important to have a supply of fresh and nutritious food in order to uplift the family nutrition and through urban agriculture, kitchen wastage can be re-used such as fertilizer and pots for plants and also, urban agriculture helps to keep the environment cleaner, greener and cooler. It is interesting to see that both urban women farmers and urban women non-farmers believed that urban agriculture doesn't have the ability of converting the fast burning food habits of people to slow burning food habits (Table 01).

Figure 02 depicts the factors that are chosen from the factor analysis from this scree plot

Table 01: Results of Mann-Whitney test

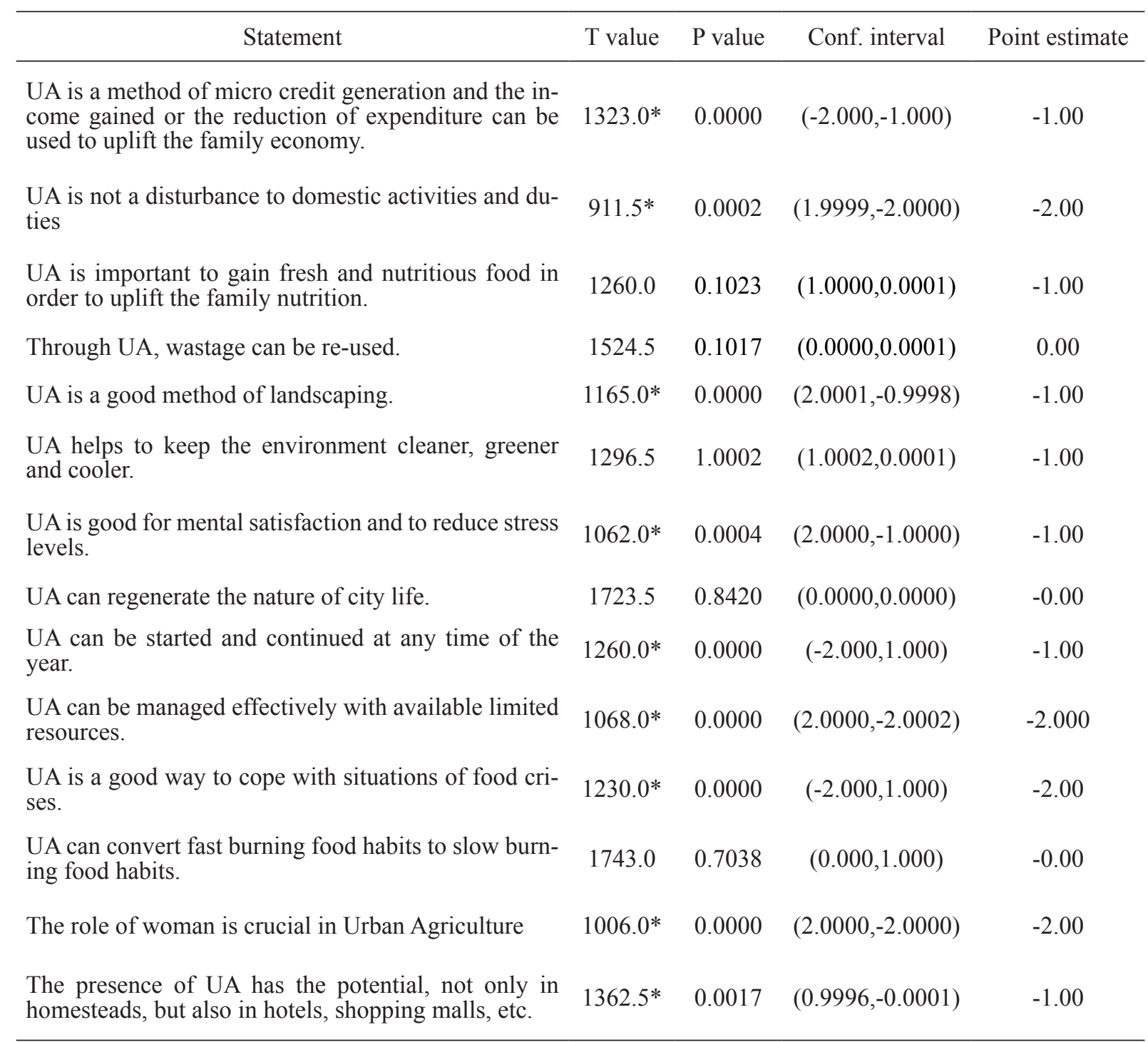

* Significant at 0.05 significance level two factor were selected according to the steep drops in the scree plot. Accordingly first two factors were chosen to represent the perception of urban women towards urban agriculture.

The results of the multivariate factor analysis in Table 02, depict that the mainly identified external factors which affect the perceptions of urban women farmers and non-farmers are, "the differences in the levels of awareness about urban agriculture" and "the strong societal negative beleif that urban agriculture is not capable of saving cities from environmental pollution and build up a green urban environment".

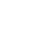




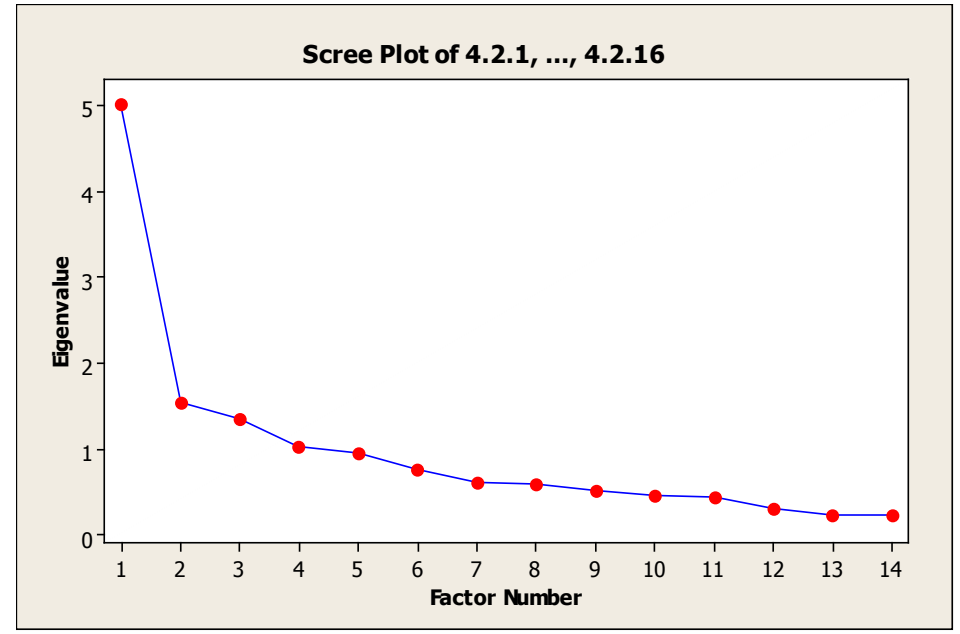

Figure 02: Scree plot of the perception variables on urban agriculture

Table 02 : Rotated Factor Loadings and Communalities (Varimax Rotation)

\begin{tabular}{|c|c|c|c|}
\hline Statement & Factor1 & Factor 2 & Communality \\
\hline $\begin{array}{l}\text { UA is a method of micro credit generation and the income gained or } \\
\text { the reduction of expenditure can be used to uplift the family economy. }\end{array}$ & 0.149 & -0.326 & 0.128 \\
\hline UA is not a disturbance to domestic activities and duties & 0.848 & -0.171 & 0.749 \\
\hline $\begin{array}{l}\text { UA is important to gain fresh and nutritious food in order to uplift the } \\
\text { family nutrition. }\end{array}$ & 0.735 & -0.104 & 0.551 \\
\hline Through UA, wastage can be re-used. & 0.346 & -0.501 & 0.37 \\
\hline UA is a good method of landscaping. & 0.792 & -0.017 & 0.627 \\
\hline UA helps to keep the environment cleaner, greener and cooler. & 0.748 & 0.166 & 0.587 \\
\hline UA is good for mental satisfaction and to reduce stress levels. & 0.851 & -0.089 & 0.732 \\
\hline UA can regenerate the nature of city life. & -0.063 & -0.795 & 0.636 \\
\hline UA can be started and continued at any time of the year. & 0.61 & 0.075 & 0.378 \\
\hline UA can be managed effectively with available limited resources. & 0.521 & -0.256 & 0.337 \\
\hline UA is a good way to cope with situations of food crises. & 0.632 & -0.236 & 0.455 \\
\hline UA can convert fast burning food habits to slow burning food habits. & 0.302 & 0.47 & 0.312 \\
\hline The role of woman is crucial in Urban Agriculture. & 0.236 & 0.193 & 0.093 \\
\hline $\begin{array}{l}\text { The presence of UA has the potential, not only in homesteads, but also } \\
\text { in hotels, shopping malls, etc. }\end{array}$ & 0.708 & 0.309 & 0.597 \\
\hline$\%$ Variance explained & 0.358 & 0.11 & 0.468 \\
\hline
\end{tabular}

\section{The effect of socio economic factors on women}

\section{participation in urban agriculture}

There is a significant relationship between the socio-economic conditions and the behavior of an individual. The personal characteristics are greatly influenced on individual behavior and his/her actions (Mahaliyanaarachchi, 2004). Therefore, it is important to study about the socio economic factors affecting the women participation in urban agriculture. Accordingly, 
age, education level, occupation, monthly income, marital status, family size, state of dependence of the members of the family, size of cultivated land and land ownership were taken as socio-economic factors. The relevance of the socio-economic factors considered in this study is justified by Mahaliyanaarachchi (2004).

Descriptive statistics in Table 03, depict that the women who were engaged in urban agriculture majority were above 55 years old and the involvement of the young women in the urban agriculture was significantly low. Contrary to this finding, Musiimenta (2002) has pointed out that, in Uganda, women in the age group 25- 44 years were more actively participated in urban agriculture than those below or above.

The majority of the women who were involved in urban agriculture were housewives. At the same time, the majority of the women who did not involve in agriculture were job holders.

About $73 \%$ of urban women farmers were engaged in subsistence farming to cater the family demand for fresh, nutritious and chemical-free food. The rest of urban women farmers sold the excess production as raw products. No one has sold the excess production as value added products. Irrespective of the age, most of the urban women farmers have participated in crop cultivation. More than $56 \%$ of the women aged above 55 years were involved in only crop cultivation and $7.32 \%$ were involved in integrated crop-livestock farming. The participation in urban agriculture of the women has been increased when their level of education is high. The results revealed that $66.7 \%$ of the women who involved in urban agriculture have completed their secondary education (Table 04).

These women farmers have spent 1-2 hours on agricultural activities irrespective of the type of farming and this time allocation is significant by house wives. It is interesting that the participation in crop farming has increased with the increment of monthly income of the family as denoted by the Table 05 . More than $19 \%$ of the urban women crop farmers were receiving an overall family income (both agricultural and non-agricultural income per month) of more than Rs.90, 000 per month. Nearly $17 \%$ were receiving an overall family monthly income in between Rs.75, 000 - 90,000. Only 7.3\% of women farmers were receiving an overall monthly family income of less than Rs.30, 000. In contrast to this finding, Flynn (2001), has pointed out that the involvement of Tanzanian people in urban agriculture is decreased with the increment of family income, as the reason behind their participation in urban agriculture is solely to cope up with rising food prices when their monthly income of the family is insufficient to do so.

\section{Model fitting to determine the level of women participation in urban agriculture}

The decision of women to participate in urban agriculture significantly depends on their socioeconomic conditions. As mentioned before, Mahaliyanaarachchi (2004) has revealed that there is a significant relationship between the socio-economic conditions and the behaviors and actions taken by them.

Table 03: Cross tabulation of participation in urban agriculture with age

\begin{tabular}{|c|c|c|c|c|c|c|c|c|c|c|c|c|}
\hline \multirow[b]{2}{*}{ Age } & \multicolumn{3}{|c|}{ Level of farming } & \multicolumn{3}{|c|}{ Type of farming } & \multicolumn{6}{|c|}{$\begin{array}{l}\text { Daily time allocation on UA } \\
\text { (in hours) }\end{array}$} \\
\hline & 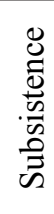 & 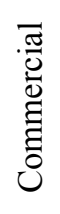 & $\stackrel{\pi}{0}$ & 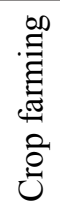 & 总 & $\stackrel{\pi}{0}$ & $\begin{array}{l}\vec{w} \\
\text { d } \\
-\end{array}$ & $\stackrel{\sim}{-}$ & 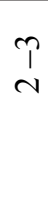 & $\begin{array}{c}T \\
m\end{array}$ & 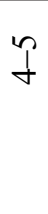 & 胥 \\
\hline Between 35 to 55 & 8 & 7 & 15 & 9 & 6 & 15 & 8 & 3 & 2 & 0 & 2 & 15 \\
\hline Above 55 & 22 & 4 & 26 & 23 & 3 & 26 & 2 & 13 & 6 & 5 & 0 & 26 \\
\hline Total & 30 & 11 & 41 & 32 & 9 & 41 & 10 & 16 & 8 & 5 & 2 & 41 \\
\hline
\end{tabular}


Table 04: Cross tabulation of participation in urban agriculture with level of education

\begin{tabular}{|c|c|c|c|c|c|c|c|c|c|c|c|c|}
\hline \multirow[b]{2}{*}{ Level of Education } & \multicolumn{3}{|c|}{ Level of farming } & \multicolumn{3}{|c|}{ Type of farming } & \multicolumn{6}{|c|}{$\begin{array}{l}\text { Daily time allocation on UA } \\
\text { (in hours) }\end{array}$} \\
\hline & 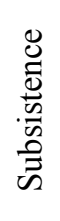 & 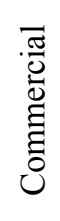 & 吾 & 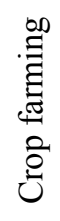 & 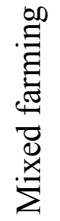 & $\begin{array}{l}\bar{\sigma} \\
0 \\
0\end{array}$ & $\pi$ & $\hat{i}$ & $\hat{\hat{\lambda}}$ & $\begin{array}{l}\stackrel{\lambda}{\hat{1}} \\
\stackrel{m}{m}\end{array}$ & $\begin{array}{l}\hat{\hat{t}} \\
\hat{t}\end{array}$ & 吾 \\
\hline Primary Education & 7 & 3 & 10 & 7 & 3 & 10 & 1 & 3 & 2 & 3 & 1 & 10 \\
\hline Secondary Education & 23 & 8 & 31 & 25 & 6 & 31 & 9 & 13 & 6 & 2 & 1 & 31 \\
\hline Total & 30 & 11 & 41 & 32 & 9 & 41 & 10 & 16 & 8 & 5 & 2 & 41 \\
\hline
\end{tabular}

Table 05: Cross tabulation of participating in UA with monthly income of the family

\begin{tabular}{lcccccc}
\hline & \multicolumn{3}{c}{ Type of farming } & \multicolumn{3}{c}{ Level of farming } \\
\cline { 2 - 7 } Monthly Household Income & $\begin{array}{c}\text { Crop } \\
\text { farming }\end{array}$ & $\begin{array}{c}\text { Mixed } \\
\text { farming }\end{array}$ & Total & Subsistence & Commercial & Total \\
\hline $\begin{array}{l}\text { Between Rs.30,000 and } \\
45,000\end{array}$ & 2 & 0 & 6 & 2 & 0 & 6 \\
$\begin{array}{l}\text { Between Rs.45,000 and } \\
60,000 .\end{array}$ & 2 & 1 & 3 & 2 & 1 & 3 \\
$\begin{array}{l}\text { Between Rs.60,000 and } \\
75,000\end{array}$ & 5 & 1 & 3 & 5 & 1 & 3 \\
$\begin{array}{l}\text { Between Rs.75,000 and } \\
90,000\end{array}$ & 6 & 2 & 7 & 6 & 2 & 7 \\
Above Rs. 90,000 & 17 & 5 & 22 & 15 & 7 & 22 \\
Total & 32 & 9 & 41 & 30 & 11 & 41 \\
\hline
\end{tabular}

The behavior of an individual is greatly affected by the personal characteristics. Based on this concept, a model was fitted to determine the level of women participation in urban agriculture. Since the dependent variable or the decision to participate in urban agriculture is categorical, a logistic regression was used in this regard. Logistic regression analysis is used to examine the influence of different factors on a dichotomous outcome (Hosmer, 2013). This is done by estimating the probability of the occurring the event by examining the relationship between the log odds of the dichotomous outcome and one or more independent variables. In this regard, calculation of changes in the dependent's log odds as opposed to the dependent variable is done (Hosmer, 2013). The log odds ratio is the ratio of two odds. It is a summary measure of the relationship between two variables. A simple description about the probabilistic relationship of the variables and the outcome, in comparison to a linear regression can be obtained from the $\log$ odds in logistic regression. Though this description is simple, it draws rich information (Anderson,1982).

The logit link has the following form:

$$
\operatorname{Logit}(P)=\log \left[\frac{P}{1-P}\right]
$$


The odds of the event's occurrence are mentioned within square brackets (Tranmer, 2008). In this model, most of the explanatory variables were also categorical. So, dummy variables were used to contrast the different categories. For each variable, a baseline category was chosen. All remaining categories were contrasted with the base line (Tranmer, 2008).

The fitted logit model is as follows:

\section{Urban Agriculture particpatio $(Y$ or $N)=$}

$-21.521+0.337$ Family $_{\text {Size }}+0.004$ Area $_{\text {Cultivated }}$ $-0.608 E d u 1-21.812 E d u(2)+20.039$

$\operatorname{age}(1)+20.834$ Age (2)

Column "B" of the Table 06 shows the coefficients of the variables. The column "Exp(B)" shows the relative odds (odds ratio). This indicates that, for each unitary increment of family members, woman head of the household is 0.103 times more likely to participate in urban agriculture. At the same time, Column "Sig" shows the significant value of each variable which was used to determine whether the variable should be included in the model or not. Accordingly, the most influential socioeconomic factors on the women participation in urban agriculture were included in the model.

\section{The suitability of the model}

The results of the classification table depicted under Table 07, shows the extent to which the model accurately predicts the dependent variable. In other words, it shows how accurate the model is at predicting whether or not an urban woman, is likely to participate in urban agriculture. This is calculated by comparing the predicted score of the individual urban woman (as either participating or not participating in urban agriculture) on the basis of the four independent variables in the model (number of members in the family, total cultivated area, education level and age), with their actual group membership as given by the data. Actual group membership means what the data tells about whether women have actually said they participate in urban agriculture or not participate in urban agriculture. The overall percentage is given as $75.6 \%$ which depicts that $75.6 \%$ of urban women have been accurately classified as either participating in urban agriculture or not, on the basis of four variable model.

\section{Strategies to uplift family economy through economic benefits obtained by urban agriculture}

Urban agriculture poses various benefits to urban women. Economic benefits, social benefits, food security, nutrition and better family health can be identified as the main benefits from urban agriculture. Among those benefits, the economic benefit receives less attention. However, Smit et al., (2001) have proved that economic benefits of urban agriculture are essential as the environmental and nutritional benefits. Food has been identified as the largest component of the urban economy of the developing world and is one of the top three components of the urban economy of developed counterparts. According to Smit et al., (2001), the major economic benefits of urban agriculture are income generation, employment, land-use economies and the development of national agriculture sector. Urban agriculture is a successful strategy for micro credit generation in household and also it is crucial to reduce the expenditure on food consumption of the family (Kutiwa et al., 2010).

Figure 03 depicts that the monthly outflow on family food consumption has been significantly reduced due to the production from Urban Agriculture. The highest expenditure reduction is from vegetables. In average, $51.42 \%$ of expenditure on vegetables has been reduced by the urban women farmers due to Urban Agriculture practices. Average monthly disbursement reduction for fruits, meat and milk were respectively; $25.93 \%, 11.74 \%$ and $10.75 \%$. Due to null involvement in aquaculture, no cost reduction for fish could be seen. Table 08 denotes the percentage of expenditure reductions due to the involvement of urban agriculture activities. 
Table 06: Variables in the Logit Model

\begin{tabular}{lrrrrrr}
\hline & B & S.E. & Wald & df & Sig. & Exp(B) \\
\hline Family Size & 0.337 & 0.207 & 2.663 & 1 & 0.103 & 1.401 \\
total cultivated area & $0.004^{*}$ & 0.002 & 3.188 & 1 & 0.074 & 1.004 \\
education & & & 0.648 & 2 & 0.723 & \\
education(1) & -0.608 & 0.755 & 0.648 & 1 & 0.421 & 0.545 \\
education(2) & -21.821 & $1.775 \mathrm{E} 4$ & 0.000 & 1 & 0.999 & 0.000 \\
age & & & 2.219 & 2 & 0.330 & \\
age(1) & 20.039 & $1.515 \mathrm{E} 4$ & 0.000 & 1 & 0.999 & 5.046 \\
age(2) & 20.834 & $1.515 \mathrm{E} 4$ & 0.000 & 1 & 0.999 & 1.117 \\
constant & -21.521 & $1.515 \mathrm{E} 4$ & 0.000 & 1 & 0.999 & 0.000 \\
\hline
\end{tabular}

* Significant at 0.05 significance level

Table 07: Classification table of the model

\begin{tabular}{|c|c|c|c|c|c|}
\hline & \multirow[t]{3}{*}{ Observed } & & \multicolumn{3}{|l|}{ Predicted } \\
\hline & & & \multicolumn{2}{|l|}{ Participation in UA } & \multirow{2}{*}{$\begin{array}{l}\text { Percentage } \\
\text { Correct }\end{array}$} \\
\hline & & & Did not participate & participated & \\
\hline \multirow{3}{*}{ Step 1} & \multirow{2}{*}{ Participation in UA } & did not participate & 30 & 11 & 73.2 \\
\hline & & participated & 9 & 32 & 78.0 \\
\hline & Overall Percentage & & & & 75.6 \\
\hline
\end{tabular}

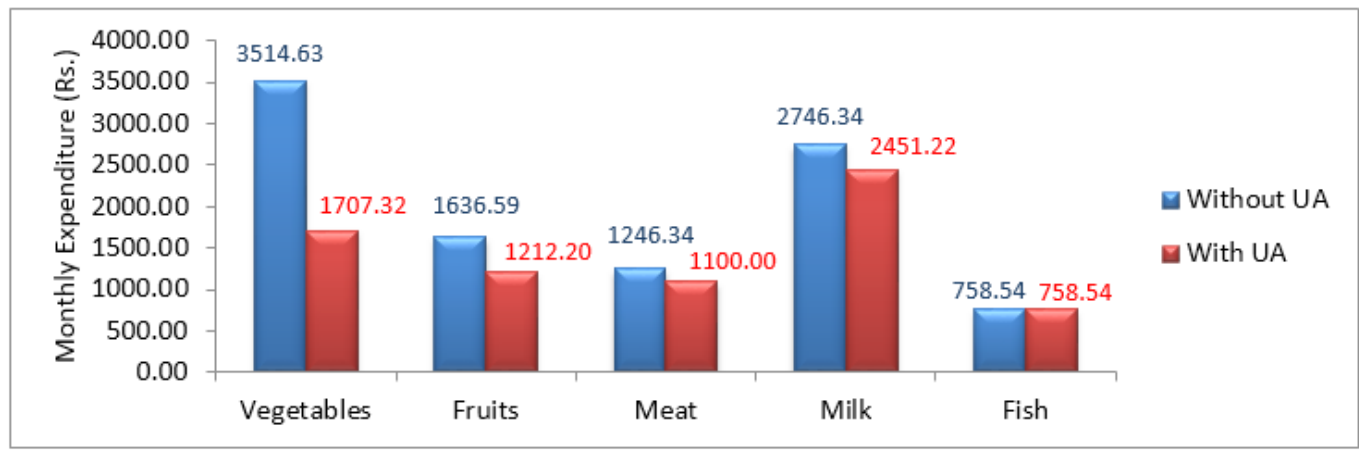

Figure 03: Average monthly expenditure on family food consumption

Table 08: Reduction of expenditure on food per month via harvest of Urban Agriculture

\begin{tabular}{cc}
\hline Food item & $\begin{array}{c}\text { Expenditure reduction per month } \\
\text { (as a percentage) }\end{array}$ \\
\hline Vegetables & $51.42 \%$ \\
Fruits & $25.93 \%$ \\
Meat & $11.74 \%$ \\
Milk & $10.75 \%$ \\
Fish & $0.00 \%$ \\
\hline
\end{tabular}


Nugent (2000), has revealed that urban families who are not participating in urban agriculture spend $60-80 \%$ of their family monthly income on purchasing food and yet the food security is not ensured. On the other hand, urban agriculture can be used as a good strategy to make a difference to those who are participating in it. This proves the contribution of urban agriculture to uplift the family economy is significant and if urban dwellers participate in urban agriculture, their family expenses for food stuff could be reduced considerably.

The results of the cross tabulation (Table 09) illustrates the idea of how the economic benefits obtained from urban agriculture were used to uplift the family economy. The ways of spending the savings from purchasing of food stuff due to production of urban agriculture activities by women farmers were categorized under six strategies and a ranking method was used to get the response from them. Among 41 women that were chosen, all 41 personals have ranked at least a single strategy but only 10 of them have ranked up for two and 4 people up to three strategies. Accordingly, most of the women have chosen the strategy1- Investing on the same urban agricultural activities. This shows that the major consent of urban women farmers was to improve the same agricultural activities by investing the income they get from these activities. About $32 \%$ of them have the opinion of using the saved money to purchase household possessions and $22 \%$ of them were spending on the education of children. Furthermore, among these $54 \%$ of who had chosen the strategies four and five ("purchase household possessions" and "Spending on the education of children"), around $50 \%$ of women have ranked "investing on the same urban agricultural activities" or "investing on different urban agricultural activities" as their second best option. So altogether, it can be summarized that most of the women have the idea of investing their income from agricultural activities on same agricultural activities.

Musiimenta (2002), has highlighted that urban women farmers use that saved money on other financial demands of the family such as, monthly rental of the residence, school fees of children and many more. Musiimenta (2002) also revealed that house wives whose husbands provide sufficient money for family expenses save this money on bank accounts and use it as an independent income to fulfill their personal needs and buying additional household belongings.

\section{Constraints of Urban Agriculture}

Although urban agriculture brings plenty of benefits to urban women, there are many constraints that hamper the women participation in urban agriculture. The results of the study depict that the major constraint that hinders the women participation is "insufficient time for agricultural activities". It is a must for the woman of household to allocate more time for household care and management. Therefore they have less time for agricultural activities or other occupations. Therefore, time is insufficient factor for urban women to participate in urban agricultural activities.

Table 09: Ranks for the Strategies to uplift family economy

\begin{tabular}{lccc}
\hline Strategy & Rank 1 & Rank 2 & Rank 3 \\
\hline Investing on the same Urban Agricultural activities & 19 & 6 & 0 \\
Investing on different Urban Agricultural activities & 0 & 4 & 0 \\
Investing on other small business & 0 & 0 & 4 \\
Purchase household possessions & 13 & 0 & 0 \\
Spending on the education of children & 9 & 0 & 0 \\
\hline
\end{tabular}


Hovorka (2001), and Adedayo and Tunde (2013) have highlighted that women's decision to participate in urban agricultural activities is negatively affected by the lack of knowledge about the required quality of consumable inputs and difficulties in identifying the pathology of crops. This finding has been further proved via the depicted results of this study, since the second major constraint identified was "inability to identify diseases, pest attacks and nutrient deficiencies".

The third major drawback identified was the poor quality of the inputs such as, dissatisfactory quality of planting material and poor soil fertility. Adedayo and Tunde (2013), Kutiwa et al., (2010), Nugent (2000) have also identified that the poor quality or non-existent markets for inputs is one of the major pitfalls in urban agriculture.

Minor constraints that hamper the women efforts in urban agriculture are (from most prominent to least prominent); shortage of space, high cost for irrigation, high initial capital requirement, high labor costs and labor shortage, health problems endowed specially with livestock production such as Avian Influenza from poultry production and problems from the neighborhood such as the noise of poultry. In addition to health problems occurred by animals, Kutiwa et al., (2010), Muchuweti (2006), Maugeout (2000) revealed that the misuse or over-use of agrochemicals, the application of untreated wastes to food crops, soil and water with high heavy metal contamination and improper disposal of animal and vegetable wastes such as dumping wastes in open areas and roadsides can lead to reduction of food quality and food security (Muchuweti 2006) and also cause health hazards such as diarrhea (Kutiwa et al., 2010) .

Moreover, Adedayo and Tunde (2013), Kutiwa et al., (2010) have also identified the high cost for irrigation as well as shortage of water supply as another barrier in urban agriculture. Supporting the findings of this study, Adedayo and Tunde (2013) have also disclosed that high capital requirement and lack of credits and shortage of land and space. In addition to the constraints identified in the study, Kutiwa et al., (2010) has stated poor communication channels when selling the excess harvest and limited access to land especially the problems occurred by the owners to tenants who are urban farmers as pitfalls in urban agriculture at Belgium. Moreover, Adedayo and Tunde (2013) have also recognized seasonal rainfall, lack of storage facilities, inadequate extension, excessive pest and diseases, problems with the middlemen and marketing issues as barriers for urban agriculture in Nigeria, which have not identified through this study. Hovorka (2001) has identified the opposition to city farming activities by local authorities as the biggest barrier to women urban farmers .However, the results of this study depicts that it is not a barrier for women urban farmers except the livestock farmers.

\section{CONCLUSION}

The role of woman in urban agriculture is decisive, as most of the time, the woman of the household is the one who is responsible to uplift the nutritional status of the family while partially responsible to uplift the family economy. Nevertheless, women participation in urban agriculture is noticeably poor. Time limitations, poor knowledge and skills on agriculture which has therefore lead for the inability of identifying diseases, pest attacks and nutrient deficiencies, poor quality of planting inputs are the mainly identified constraints that hinder the women's participation in urban agriculture.

Most of the urban women farmers prefer to involve in subsistence crop farming as their main purpose to cater the family demand for fresh, nutritious and agrochemical-free food. Neither value added production nor aquaculture is popular among urban women farmers mainly due to lack of knowledge and skills. Integrated crop-livestock farming was only popular among young women farmers. Elderly women 
tend to engage only in crop farming. Regardless the type or the levels of farming, women aged over 55 years more actively participate in urban agriculture than others because they have enough time to spend on agricultural activities. Most of the urban women farmers have obtained at least secondary education which proves that educated urban women do participate in urban agriculture.

Women farmers have identified urban agriculture as a good method of micro credit generation, good for mental satisfaction and the role of women in urban agriculture is essential while women non-farmers were not aware about it. In general, women who are participating in urban agriculture have a positive perception towards it whereas the counter party has a negative perception towards urban agriculture. Differences in the levels of awareness about urban agriculture and "the strong societal negative beleif that urban agriculture is not capable of saving cities from environmental pollution and build up a green urban environment" are the mainly identified external factors that affect this contrast of perceptions between urban women farmers and non-farmers.

Age, education level, number of members in the family and the total cultivated area are the most influential socio-economic factors out of nine socio-economic factors tested on the women participation in urban agriculture. Finally, the outcome of this study are undoubtedly useful in planning strategies and taking appropriate decisions to eradicate urban poverty and enhance food security and nutrition by empowering urban women as entrepreneurs in urban agriculture.

\section{REFERENCES}

Adedayo, A., and Tunde, A. M., (2013). Challenges of Women in Urban Agriculture in Kwara State, Nigeria. Sustainable Agriculture Research [online], 2(3),p8. Available at http://www. ccsenet.org/journal/index.php/sar/article/viewFile/22517/15771 [Accessed 21 Dec 2013]

Anderson, J.,(1982). Logistic regression.Handbook of Statistics [online]. North-Holland, New York, (169-191). Available from: http://www.schatz.sju.edu/multivar/guide/Logistic.pdf [Accessed 15 May 2013]

Anríquez, G., (2010). Demystifying the agricultural feminization myth and the gender burden. Background paper prepared for The State of Food and Agriculture, 11.

Baker, J.L.,(2012). Impacts of Financial, Food and Fuel Crisis on the Urban Poor. World Bank, Washington, DC. (C) World Bank. Available from: https://openknowledge.worldbank.org/ handle/10986/10067 License: CC BY 3.0 Unported [Accessed 23 Dec 2013].

Bryld, E., (2003). Potential, Problems and Policy Implications for Urban Agriculture in Developing Countries. Agriculture and Human Values [online], 20: 79-86

Bryman, A., (2012). Social research methods, Oxford university press.

Chaipa, I. and King, B., (1997). Urban Agriculture in Gweru Household Nutrition, Economic Costs and Benefits, IDRCProject No. 01015. Harare. Research, Development and Consultancy Division of Environment and Development Activities-Zimbabwe (ENDA-Zimbabwe).

Cockram, M. and Feldman, S., (1996). The beautiful city: gardens in third world cities. African Urban Quarterly. 
DeCuir-Gunby, J. T., Marshall, P. L., and McCulloch, A.W., (2012). Using Mixed Methods to Analyze Video Data A Mathematics Teacher Professional Development Example. Journal of Mixed Methods Research [online], 6(3), 199-216. Available from: http://mmr.sagepub.com/ content/6/3/199.short [Accessed 25 Dec 2013]

Department of Census and Statistics- Sri Lanka. (2012). A13 : Occupied housing units in districts ,Divisional Secretary's Divisions and GramaNiladhari Divisions by principal material of construction of wall, 2012 (Provisional). [online] Available at: http://www.statistics.gov.lk/ PopHouSat/CPH2011/Pages/Activities/Reports/cph2011Pub/hhgn1.pdf. [Accessed 21 Dec 2013].

Doss, C., and SOFA Team (2010). Roles of women in agriculture, Food and Agriculture Organization

Eawag, N., 2010. Waste resource in Agriculture, Swiss Federal of Aquatic Sciences and Technology.

Evers, H. and Ruediger, K., (1996). Subsistence production in Bangkok Development,. Seeds of Change 4 (50-55).

Flynn, K.C., (2001). Urban Agriculture in Mwanza, Tanzania. Africa, 71: 666-691.

Hampson, S., Barckly M., Andrews, J. and Lichtenstein, E., (2002). Assessing perceptions of synergistic health risk - a comparison of two scales.US National Library of Medicine and National Institute of health [online].Available from: http://onlinelibrary.wiley.com/ doi/10.1111/15396924. 00378/abstract?deniedAccessCustomisedMessage=\&userIsAuthent icated $=$ false [Accessed on 20 May 2013]

Hart, A., (2001). Mann-Whitney test is not just a test of medians: differences in spread can be important. British Medical Journal [online] (323.7309 .391). Available from: http://www. ncbi.nlm.nih.gov/pmc/articles/PMC1120984/ [Accessed 23 May 2013]

Hosmer Jr, D. W., Lemeshow, S., and Sturdivant, R. X., (2013). Applied logistic regression [online]. Wiley.com. Available from : http://books.google.lk/books?hl=en\&lr=\&id=wGO5h0Upk9g C\&oi=fnd\&pg=PR7\&dq=Hosmer+Jr,+D.+W.,+Lemeshow, + S., + and + Sturdivant, + R. + X., + 2013.+Applied+logistic + regression\&ots $=$ hkh6OCoEro\&sig $=$ wqWmrl3k1xFkrHkKEGLM U_OFpmI\&redir_esc=y\#v=onepage\&q\&f=false. [Accessed 22 Dec 2013]

Hovorka, A. J., (2001). Gender and Urban Agriculture: emerging trends and areas for future research. Annotated Bibliography on Urban and Peri Urban Agriculture. Compiled for the Swedish International Development Agency (SIDA).Leusden, Netherlands: ETC Ecoculture, 165-176.

Kutiwa, S., Boon, E., and Devuyst, D., (2010). Urban Agriculture in low income households of Harare: an adaptive response to economic crisis. Journal of Human Ecology [online], 32(2), 85-96. Available from: <http://www.krepublishers.com/02-Journals/JHE/JHE-32-0-000-10Web/JHE-32-2-000-10-Abst-PDF/JHE-032-2-085-10-2015-Kutiwa-S/JHE-032-2-085-102015-Kutiwa-S-Tt.pdf $>$ [Accessed 26 Dec 2013]

Mahaliyanaarachchi, R. P., (2004). Commercialisation of Agriculture in Sri Lanka: Two Studies in Selected Sectors. Faculty of Agricultural Sciences, Sabaragamuwa University of Sri Lanka. 
Maxwell, D., Larbi, O. W., Lamptey, G. M., Zakriah, S. and Armar-Klemesu, M. (1998). Farming in the Shadow of the City, Changes in Land Rights and Livelihoods in Peri urbanAccra, Ghana.Noguchi Memorial Institute, University of Ghana.

Mougeot, J. L., (2000). The hidden significance of Urban Agriculture. Trialog, 65, 8-13.

Mougeot, L., (2000). Urban Agriculture - Definition, Presence, potential and Risks and Policy Challenges, Growing Food.Urban Agriculture on Policy Agenda. La Ha Vana, Cuba, International Workshop on Growing cities.

Muchuweti, M., Birkett, J. W., Chinyanga, E., Zvauya, R., Scrimshaw, M. D. and Lester, J. N. (2006). Heavy metal content of vegetables irrigated with mixtures of waste water and sewage sludge in Zimbabwe: Implication for Human Health. Agriculture, Ecosystems and Environment, 112: 41-48.

Musiimenta, P., (2002). Urban Agriculture and Women's socio-economic empowerment- A case study at Kiswa and Luwafu areas in Kamapala City, Uganda. In: s.l.:Kampala.

Nugent, R., (2000). The impact of Urban Agriculture on the household and local economies, Growing cities, growing food. Urban Agriculture on the policy agenda. (67-97).

Obuobie, E., Streiffeler, F., Kessler, A., (2004). Women in Urban Agriculture in West Africa.Urban Agriculture Magazine [online], 12: 13-15.

Ranasinghe, T., (20090 Manual of low/no space agriculture -cum- family business gardens. International Water management Institute, RUAF Foundation.

Smit, J., Nasr, J. and Ratta, A., (2001). Benefits of Urban Agriculture, Urban Agriculture Food, Jobs and Sustainable Cities. The Urban Agriculture Network, Inc.

Tranmer, M. and Elliot, M., (2008). Binary logistic regression. Cathie Marsh for Census and Survey Researches.

Wilbers, J., (2004) Urban Agriculture and Gender- a conceptual frame work. RUAF Foundation, Netherlands.

Zezza, A., and Tasciotti, L., (2010) Urban Agriculture, poverty, and food security: empirical evidence from a sample of developing countries. Food Policy [online], 35(4), 265-273. Available from: http://start.org/download/urbanag/zezza.pdf [Accessed 22 Dec 2013] 